\title{
Brownish alterations on the marble statues in the church of Orsanmichele in Florence: what is their origin?
}

Daniela Pinna ${ }^{1,2^{*}}$, Monica Galeotti ${ }^{1}$ and Adriana Rizzo ${ }^{3}$

\begin{abstract}
Introduction: The paper describes the complex investigations carried out to understand the sources of the brown chromatic changes that have occurred on ten marble statues dated back to the first half of the 15th century and now located in the Church of Orsanmichele in Florence, Italy. When the statues were removed from the outdoor niches for restoration in the 1980s, they appeared covered with a dark brown patina (called 'bronzatura') that dated to interventions occurred just after 1789. Archival documents confirmed that they had been carried out to make the marble statues look like bronzes. Because of the removal of the dark patina carried out by the Opificio delle Pietre Dure in the 1990s, the marble almost regained its distinguishing clear tonality even if darker areas remained. After the statues were placed indoors at the end of restoration, brownish discolorations started to appear on their surfaces.

Results: Research began by using various non-invasive analyses (photographs under ultraviolet illumination, fluorescence lifetime imaging, $x$-ray fluorescence). The results of UV fluorescence tests and FLIM showed that the fluorescence emission's distribution map does not have distinctive and homogeneous characteristics in relation to the areas with the discoloration. Therefore, it is not a superficial film, but rather a phenomenon affecting the marble structure. Then we performed invasive analyses on samples from some statues. The results of optical microscopy, ATR-FTIR and Raman spectroscopy on cross sections, pyrolysis-gas chromatography/mass spectrometry on powdered samples from the surfaces and/or the bulk of the marble allowed the identification of the various substances involved in the chromatic alteration. Most important was the detection of weddellite and gypsum on the surface and within the marble. This finding, combined with the presence of lipids inside the stone, suggests that mineralization of treatments have occurred, causing discolorations.
\end{abstract}

Conclusions: Even though the study focuses on the statues from Orsanmichele, their issue nevertheless should not be considered specific to them. Marble discolorations are a widespread phenomenon whose complete understanding needs a complex series of analyses and only the combination of non-invasive and invasive analyses can fulfill this goal.

Keywords: Marble discolorations, Calcium oxalates, Statues, Bronze-like patina, Non-invasive and invasive analyses, Treatments

\footnotetext{
* Correspondence: daniela.pinna@beniculturali.it

${ }^{1}$ Opificio delle Pietre Dure, viale Filippo Strozzi 1, 50129 Florence, Italy

${ }^{2}$ Soprintendenza per i Beni Artistici e Storici, via Belle Arti 56, 40126 Bologna,

Italy

Full list of author information is available at the end of the article
}

\section{Chemistry Central}

(c) 2015 Pinna et al.; licensee Springer. This is an Open Access article distributed under the terms of the Creative Commons Attribution License (http://creativecommons.org/licenses/by/4.0), which permits unrestricted use, distribution, and reproduction in any medium, provided the original work is properly credited. The Creative Commons Public Domain Dedication waiver (http://creativecommons.org/publicdomain/zero/1.0/) applies to the data made available in this article, unless otherwise stated. 


\section{Introduction}

Discolorations are often encountered on stone surfaces of sculptures housed indoor or exhibited outdoor and then re-located indoor. Among the available stones, marble is one of the most used by artists of all times to carve sculptures. Therefore, the study of marble discolorations, typically ranging from black to grey and from brown to orange, is a relevant subject in the field of conservation of cultural heritage. Although discolorations, and in particular brown discolorations, represent a widespread alteration, scientific literature on this specific subject is limited. While in some instances technical investigations clearly identified the causes of the discolorations, in many other cases they are still debatable.

Research has shown, so far, that different factors contribute to stains and discoloration on marble. The more complete studies found a correlation between marble discoloration and metals. When stone artefacts have metal components, either as part of the object or as elements inserted into the stone (bars, rods or pins), stains can be produced as a result of metal ions released in the stone [1].

Iron-containing minerals are present in marble to various degrees and include mainly iron sulphides (e.g. pyrite, marcasite), iron carbonates (siderite) and ferromagnesian silicates (biotite, hornblende) [2]. They occur dispersed or concentrated along veins in the natural stone. Staining forms when water transports iron to the marble surface, where it is precipitated as colored iron hydroxide (limonite) $[2,3]$.

The discolorations are a problem also in modern buildings as they damage the aesthetic characteristics of stone. A research [2] showed that uniformly white Carrara marble samples changed into a uniformly yellow-orange color when treated with an alkaline solution. The discoloration depended directly on the oxidation of pyrite and hematite minerals dispersed in the marble. Although the oxidation of pyrite crystals is a natural process, basic aqueous solutions increased the rate of oxidation [4].

Besides the oxidation of metal components in the stone, the staining can be originated by the reaction of organic matter, trapped during sedimentation and lithification of the rock, and alkalis from the cement [2].

Structural, textural and/or material transformations can cause thin coloured patinas $(20-200 \mu \mathrm{m})$ on marble surfaces [5]. Patina is an all-embracing term in the terminology of surface changes of materials due to natural ageing by chemical-physical reactions going on near, at and above the original surface of a stone. These includes interaction between the surface of the stone and the environment, biological activity, as well as ancient protective treatments [6]. These aging processes can manifest themselves as films and external deposits. Their color varies from black to grey, from brown to orange, and can derive from many substances (fly-ash or other dust, biominerals formed by microbiological activity, Fe content of such minerals, organic pigments like melanins, melaninoids, humic substances, rusty decay products of chlorophyll).

Discolorations may also appear as an effect of cleaning during restoration. The application of a mixture of acetone/ammonium carbonate is a quite common method for cleaning marble. It is not chemically stable and tends to change colour over time. It turns yellow after a few days and red-brown after two to three weeks [7]. A few days after treatment, marble samples treated with acetone/ammonium carbonate develop yellow-orange microscopic spots.

Although a number of papers deals with the yellowing induced on marble by laser cleaning, it is not yet clear whether the effect is caused by the laser itself or by the interaction between marble and substances formed or transformed by laser activity (such as atmospheric particles, pre-existing patinas or previous restoration treatments [8]). Some authors state that soiling residues and deposited/re-deposited laser-ablated products can cause yellowing, while other authors identify iron content located in nanometer-sized spheres on the surface as the source. Moreover, the light scattering resulting from voids, irregularities or small cracks formed by the selective removal of the gypsum encrustation can be a cause ([9-11].

Multiple causes of discolorations emerged from a study focused on the renowned Indian monument Taj Mahal [3]. Different forms of staining appeared over time on marble surfaces, i.e. uniform yellowing particularly in the niches and the arches, brown rust-like stains, yellow-grey deposits, brown spots, black patches. No sulphates were detected. Analyses indicated that the yellowing was due to residues of polymethyl methacrylate resin and to calcium oxalates, the latter derived from oxalic acid and ammonium oxalate commonly used in India to clean masonry. The source of brown spots was the iron minerals present in the marble structure while the black patches, limited to the areas that remain wet for long periods, were caused by biofilms.

Concerns about staining of marble because of treatments were sensed also in the 19th century. Oddy [12] reports a letter dated March 1858 by a restorer who was in charge of some interventions on marble sculptures of the British Museum in London. He wrote, 'I think it is my duty to say that some of the works are much damaged by ignorant or careless moulding (with oil and lard) and by restorations in wax, and wax and resin. These mistakes have caused discoloration'. It is a relevant document because it informs us about substances such as oil, lard and wax used in the past on marble for various reasons.

The present paper describes the complex investigations carried out to understand the sources of the brown chromatic changes that have occurred on ten marble 
statues dated back to the first half of the 15th century and now located in the Church of Orsanmichele in Florence, Italy. Originally located in exterior niches of the Church, the marble statues had suffered from several extensive alterations that made their restoration necessary. After the restoration in the 1990s, it was decided that the sculptures should not be returned to their original outdoor locations, but instead they should be displayed in a museum created for them in the interior of Orsanmichele, in the large Gothic vaulted room on the second floor, and replaced with replicas in the original positions.

After the statues were located indoors, brownish chromatic changes started to appear on their surfaces. Some of the faces of the figures are now almost completely brown, strongly altering the clear tone and translucency characteristic of the marble.

In order to address this issue, research began by using various non-invasive analyses (photographs under ultraviolet light, fluorescence lifetime imaging FLIM, X-ray fluorescence) as well as measurements of the climatic conditions (data not reported) to obtain the most data for each statue and its environment [13].

Then we performed invasive analyses on samples from some statues. We combined the results of SEM-EDX, ATR-FTIR and Raman spectroscopy on cross sections, with the results of pyrolysis-gas chromatography/mass spectrometry (py-GC/MS) of powders from the surfaces and/or the bulk of the samples. The non-invasive and invasive techniques allowed the identification of the various substances involved in the chromatic alteration. Even though the study tries to answer question about the discoloration of the statues of Orsanmichele, the analytical techniques used and the findings make the topic of much broader interest. In addition, some general issues emerge from our study. Firstly, marble discolorations are a widespread phenomenon, whose complete understanding needs a complex series of analyses. Only the combination of noninvasive and invasive analyses can fulfill this goal. Fluorescence lifetime imaging, for example, is a very useful technique because it maps non-invasively the discolorations and informs on differences in composition, which can then be characterized by other techniques at molecular and atomic level. Secondly, this study illustrates one of the common problems encountered by conservators dealing with the preservation of stone heritage: the interaction of human interventions (from cleaning to esthetic and/or conservative treatments) and environmental conditions with the stone and with each other. Even though stone statues are indoors, their conservation is not a foregone conclusion. In the case of Orsanmichele statues the room in which they are located has large windows on all four walls, which let in a lot of light, and one door leading directly to the outside. The windows cannot be opened and are partially screened by curtains. They have a big significant effect on the museum's climatic conditions and cause overheating during some periods of the warmer months as microclimatic measurements carried out between November 2004 and July 2006 showed [13].

The discoloration of marble, and in particular that of the Orsanmichele statues represents a broad and largely obscure issue, highlighting the vulnerability of these masterpieces. It is a crucial topic, worth of being studied in depth, for the preservation of the Orsanmichele statues and of other marble sculptures, in general, for the future.

\section{Historical and conservation background}

The building of Orsanmichele, completed in 1404, became a representative and religious establishment thanks to the generosity of the Florentine Guilds, who decorated it between the 14th and 16th century with extraordinary sculptures and paintings. Today, the whole building is a museum on its own. The second floor currently exhibits the statues, in marble and bronze, which once adorned the outside niches dedicated to the Guilds. The statues include masterpieces from the foremost Florentine artists of the 15th (Nanni di Banco, Ghiberti, Donatello) and 16th century (Giambologna).

The restoration directed by Annamaria Giusti (Opificio delle Pietre Dure) of ten stone statues that dated back to the first half of the 15th century (see Table 1) began in 1984 with Donatello's San Marco and ended in 1999 with Nanni di Banco's Quattro Santi Coronati. This intervention turned into an opportunity for studying both the sculptures' condition and treatments conducted in the past and poorly documented. In some cases, then-innovative restoration techniques were experimented, like the use of laser for cleaning gilded areas that had survived [14].

When the statues were removed from the niches for restoration, they appeared covered by a dark brown patina that was absent only from the areas that jutted out from the niches (Figure 1a). The only statue not treated with this patina was the Madonna della Rosa, attributed to Simone di Ferrucci, which was located indoors from 1628 until about 1925 when it was again placed outdoors. After the restoration treatment (Figure 1b), some areas with patina were left on the statues as reference. Archival documents confirmed that the patina (called 'bronzatura') dated to treatments that occurred just after 1789, which had been carried out to make the marble statues look like bronzes. The modification of statues' appearance applying antiquing bronze-like patinations was a treatment quite common during the eighteenth and nineteenth centuries in Italy and noted by Giusti in other statues $[15,16]$.

The statues were treated again sometime between the end of 1800 and the beginning of 1900 . A comparison between photographs taken by Alinari in 1880s and 1910s allowed to hypothesize that in that period a new treatment 
Table 1 List of statues analyzed and history of their treatments

\begin{tabular}{|c|c|c|c|c|}
\hline Statue & Bronze-like patina & Physical/ mechanical & Chemical & Molding \\
\hline $\begin{array}{l}\text { Madonna della Rosa } \\
\text { attributed to Simone di } \\
\text { Ferrucci } 1399\end{array}$ & No & Dusting with brushes. & $\begin{array}{l}\text { Poultices with anion-exchange } \\
\text { resins. Cotton swabs with turpentine } \\
\text { in areas with gilding. Final coating } \\
\text { with microcrystalline wax. }\end{array}$ & $\begin{array}{l}\text { Fluoroelastomer Akeogard CO 10\% } \\
\text { in acetone (protective barrier), } \\
\text { microcrystalline wax (detaching } \\
\text { material), silicone rubber to take } \\
\text { the mold. Gilding areas protected } \\
\text { with microcrystalline wax. }\end{array}$ \\
\hline
\end{tabular}

S. Eligio by Nanni di Yes Banco ca.1417-1421

\section{San Giacomo}

Yes

Maggiore by Niccolò

di Pietro Lamberti ca. 1414

San Filppo by Nanni Yes di Banco 1410

\section{Quattro Santi} Yes

Coronati by Nanni di

Banco ca.1409 - 1417

(group of four statues)

San Pietro attributed to Filippo Brunelleschi ca. 1421

San Marco by

Donatello ca. 1413
Air-abrasive with aluminum oxide powder.

Air-abrasive with aluminum oxide powder.

Air-abrasive with aluminum oxide powder. Gilded areas: Laser Nd:YAG (1064 nm) and $\mathrm{Nd}$ :YAP (1340 nm).

Final cleaning of non-gilded areas with rotating siliconic device. Gilded areas: Laser $\mathrm{Nd}$ :YAG (1064 nm) and $\mathrm{Nd}$ :YAP (1340 nm).

Yes Air-abrasive with aluminum oxide powder.

Air-abrasive with aluminum oxide powder.
Sepiolite poultice with ammonium carbonate in some areas. On the back, poultice with distilled water.

\section{Unknown (old treatment)}

As for Madonna della Rosa

As for Madonna della Rosa

Poultice with 7\% aqueous EDTA (slightly alkaline $\mathrm{pH}, 40 \mathrm{~min}-24 \mathrm{hrs}$ ) Deionized water.

As for Madonna della Rosa

Sepiolite poultice with

As for Madonna della Rosa ammonium carbonate in some areas. On the back, poultice with distilled water. Gilded areas: silica gels with sodium carbonate, poultice with ammonium carbonate. Consolidation with methyl organo-silicone resin (Rhodorsil 4673) in limited areas.
As for Madonna della Rosa 
was applied because the recent images show a more extended and polished black patina on the surfaces. Diagnostic analyses (FTIR, SEM-EDX) of the bronze-like patina performed by Matteini and co-authors [16] showed that it consisted of ochre and brown earth colours, plant gums, and other unidentified organic substances. Calcium oxalate was detected in layers under this patina, indicating that an organic substance had been applied as a protective barrier, and over time, this reacted with the marble and mineralized into calcium oxalate. Matteini and co-authors [15] correlated the new treatment with a second calcium oxalate layer laying on the ancient one and containing traces of pigments. Moreover, diagnostic analyses (optical microscopy, SEM-EDX) revealed the survival of gilding on localized areas and features on the statues' surfaces, such as the hair, beards, edges of robes, books and sandals, which were originally gilded [15]. No evidence of polychromy were found on the surfaces of any statue with the exception of Sant'Eligio, more Gothic-styled than the other statues, that presented traces of azurite [15].

Each statue was restored at different times and using different techniques (Table 1), mostly mechanical methods (air-abrasive with aluminum oxide powder) but also poultices with anion-exchange resins, with 7\% aqueous EDTA and with ammonium carbonate in limited areas. Laser cleaning allowed recovering of all the traces of gilding and its underlying preparation. The most damaged parts of some statues were consolidated with a silicone resin while the only sculpture receiving a complete final protection with microcrystalline wax was the Madonna della Rosa. Finally, molds of all the statues, with the exception of Nanni di Banco's Sant'Eligio, whose replica already existed, were carefully carried out in silicone rubber. Before the mold was taken, a fluoroelastomer was applied as a protective barrier followed by microcrystalline wax as a detaching material, according to a protocol developed by the Opificio to avoid any chromatic changes or other alterations on the statue's surfaces [17-19].

The general result of the restoration was the return of all statues to the bright colour of the marble, which regained its distinguishing pale tonality (Figure 1b), even though in some cases unavoidable chromatic inhomogeneity remained, particularly caused by the past treatments. However, after the statues were placed in the interior of Orsanmichele, brownish alterations developed on their surfaces darkening the areas with chromatic inhomogeneity. On several statues, these alterations worsened over time in either extent or tonality, so that some of the faces are now very disfigured (Figure 1c). The research on the sources of the brownish alteration was quite complex because it did not seem to relate to a superficial film but rather to a phenomenon affecting the marble inside and scientific literature on the subject is limited.

\section{Methods}

Non invasive techniques (UV fluorescence imaging, FLIM, XRF)

Measuring fluorescence emission of a material after ultraviolet (UV) excitation with a portable fluorescence system is a well-established, non-invasive technique. Because different materials exhibit characteristic fluorescence colours when exposed to UV illumination, this analysis allows on-site identification of the distribution of organic substances using images that are recorded by a digital imaging device. UV Fluorescence (UVfl) images were acquired with a CMOS digital camera Nikon D7000 equipped with UVCut Schott KV418 filter. UV illumination was produced using two Wood lamps (each made of four Philips tubes of 18 W). Labsphere Spectralon $^{\bullet}$ was used as a reference. In order to avoid any interference of environmental visible light to the images, a screened box was properly designed for recording the UV images.

Fluorescence Lifetime Imaging (FLIM) is a spectroscopy fluorescence technique that can measure the speed of decay in the fluorescence emitted by the surfaces under examination [20]. It provides the fluorescence amplitude map and the lifetime map of a surface of interest after excitation with very short UV pulses. The amplitude map is mainly correlated with the amount of fluorescent materials present on the surfaces, while the lifetime map indicates areas characterized by the presence of different fluorescent compounds, since any material usually exhibits a specific and characteristic fluorescence lifetime. The measurement allows for a more precise differentiation of various substances that may appear similar under UV illumination. The apparatus employs a Nitrogen pulsed laser $(\lambda=$ $337 \mathrm{~nm}$ ) and a nanosecond time-gated intensified camera for recording the temporal decay of fluorescence. It can examine an area of about $25 \mathrm{~cm}$ diameter and can produce a colour-coded map of the fluorescence emission, measured in nanoseconds (ns). UV fluorescence imaging and FLIM techniques were carried out on six statues.

X-ray fluorescence (XRF) measurements with a portable device were performed on 35 spots scattered over seven sculptures. Energy-dispersive $\mathrm{x}$-ray fluorescence is a technique that detects chemical elements by measuring the energy and intensities of $\mathrm{x}$-ray spectral lines emitted under irradiation with a primary beam of x-rays or gamma rays. Accessibility of some parts of the sculpture (folds, hidden and jutting parts) constrained the positioning of the XRF head and thus limited the number of areas investigated. When possible, we performed the measures on dark and lighter areas close to each other to highlight their chemical differences. We used an Assing, Lithos 3000 instrument with a silicon chamber detector and a molybdenum X-ray tube voltage $(24 \mathrm{kV})$. The parameters were: current $300 \mu \mathrm{A}$ and $120 \mathrm{~s}$ live time. The areas selected for analysis were $1 \mathrm{~mm}$ diameter. $\mathrm{K} \alpha \mathrm{X}$-ray lines were analysed except for lead ( $\mathrm{M} \alpha$ lines). The spectra were processed using Qxas software by IAEA. 


\section{Invasive techniques (optical microscopy, FTIR, ATR-FTIR, micro-Raman, py-GC/MS)}

In order to better understand the discoloration phenomenon at the surface and the bulk of the marble it was necessary to analyse samples removed specifically from brownish areas and compare them to those from brighter and untreated areas. Scrapings of the bronzelike patina were also analysed. Samples collected from seven sculptures were first observed under a stereomicroscope Zeiss Stemi 2000-C. Fragments of the marble samples were embedded in acrylic resin (Technovit 2000LC, Kultzer, Germany). The embedded samples were dry-ground and polished using polishing cloths of grades 1500-12000 (Micro-Surface finishing products Inc., Wilton, IA, USA). The cross sections were examined at the microscope Zeiss Axioplan 2, which features a halogen bulb and a mercury lamp for visible and ultraviolet illuminations, respectively. Digital images were taken with a Spot Pursuit camera (Diagnostics Instruments), attached to the microscope and were acquired using Spot Advanced software.

Fourier transform infrared micro-spectroscopy was first performed on scrapings of the marble bulk and of the surfaces and crusts. Brown grains of the samples were selected under the stereomicroscope, flattened on a $\mathrm{KBr}$ support and analysed by transmission with a Nicolet Nexus Fourier Transform Infrared Spectrometer (FT-IR) with a spectral resolution of $4 \mathrm{~cm}^{-1}$ (128 scans), spectral range $400-7000 \mathrm{~cm}^{-1}$, background on $\mathrm{KBr}$, square spot size ranging from 10 to $100 \mu \mathrm{m}$ in side.

However, more information could be obtained from analysis of samples prepared as cross sections. Selected cross-section samples were analysed using attenuated total reflection-FTIR (ATR-FTIR), Raman micro-spectroscopy, and FT-Raman (results not shown).

ATR-FTIR measurements were performed on individual areas in cross-sections using a $20 \times$ ATR objective, featuring a germanium crystal. The set-up used was a Hyperion 1000 microscope interfaced to a Vertex 70 spectrometer featuring a MCT (mercury cadmium telluride) detector, liquid nitrogen cooled (all by 50xBruker Optics). Acquisitions were performed in the range of $4000-600 \mathrm{~cm}^{-1}$ at a resolution of $4 \mathrm{~cm}^{-1}$. Each spectrum is the sum of 250 scans.

Raman micro-spectroscopy was performed on the same cross section observed under the microscope using a Renishaw Raman System 1000, featuring a Leica DM LM microscope. A $785 \mathrm{~nm}$ laser beam was used. Analysis were conducted with a $50 \times$ objective, with spatial resolution on the order of $3 \mu \mathrm{m}$, laser power ranging between 0.2 and $4 \mathrm{~mW}$ and 10-120 seconds acquisition time.

Selected scraping samples were analyzed by pyrolysis gas chromatography/ mass spectrometry (py-GC/MS) with methylation with (tetramethyl) ammonium hydroxide (TMAH), also called thermally assisted hydrolysis and methylation- GC/MS (THM-GC/MS). Because the technique can detect organic materials, such as lipids, protein, polysaccharides, natural and synthetic resins, waxes and some inorganics (e.g. sulphates and phosphates) it was hoped to obtain the most information on the composition of the sample in a single analysis. The sampling included scrapings from areas where the 'bronzatura' was left intact, samples from areas where the marble had darkened and samples from the whitish area of marble from Sant'Eligio and from the Madonna della Rosa. The various fragments taken from five statues were also representative of surfaces that had undergone different cleaning treatments.

Samples on the order of $100 \mu \mathrm{g}$ (crusts/ patina) to $12 \mathrm{mg}$ (bulk of marble) were used. The samples were accurately weighed on an Ultramicrobalance UMX2 (Mettler Toledo) in the pyrolysis cup (Eco-cup, Frontier lab). 3-10 $\mu \mathrm{L}$ of TMAH solution ((tetramethyl) ammonium hydroxide $25 \%$ in methanol) were added to the sample prior to pyrolysis at $550^{\circ} \mathrm{C}$ in the vertical micro-furnace of the double-shot 2020iD pyrolyzer (Frontier lab). The micro-furnace is interfaced to the gas chromatograph Agilent 6890 coupled with the Agilent 5973Network Mass Selective Detector. The analysis was carried out in split mode $10 / 1 ; 20 / 1$, or $30 / 1$ according to the sample size. A J\&W DB-5MS capillary column $(30 \mathrm{~m} \times 0.25 \mathrm{~mm} \times 0.25 \mu \mathrm{m})$ was used. The inlet was kept at $320^{\circ} \mathrm{C}$ and the MS transfer line at $320^{\circ} \mathrm{C}$. Helium was used as the carrier gas, constant flow $1.5 \mathrm{ml} / \mathrm{min}$. The GC oven temperature program was: $40^{\circ} \mathrm{C}$ for $1 \mathrm{~min}$ ramped to 320 at $10^{\circ} \mathrm{C} / \mathrm{min}$, followed by $11 \mathrm{~min}$ isothermal period. Acquisition was performed in SCAN mode ( $\mathrm{m} / \mathrm{z} 29-550)$. Temperatures at MS source was $230^{\circ} \mathrm{C}$ and at quadrupole $150^{\circ} \mathrm{C}$. A solvent delay of 1.5 min was used for most analyses.

\section{Results and discussion \\ Non-invasive techniques}

The measurement of the fluorescence emission of surfaces of the statues after ultraviolet (UV) excitation with a portable fluorescence system showed their different response to UV radiation. The head of San Pietro is a noteworthy example. The strong brown alteration of the face, hair, and beard observed in visible light (Figure 2a) yields quite a low fluorescence signal and a colour varying from dark yellow to dark brown (Figure 2b). By contrast, the tip of the nose shows an intense blue emission, similar to the zones where the brownish alteration is absent or where the surface is fractured. To ascertain the possibility of obtaining more information about the zones that appear dark yellow and dark brown in UV light, we turned to fluorescence lifetime imaging (FLIM), which can identify areas of similar molecular composition and can produce a colour-coded map of the fluorescence emission, measured in nanoseconds (ns). Lifetime values of $4.0-5.0 \mathrm{~ns}$ are generally correlated with the presence of salts, particulate 

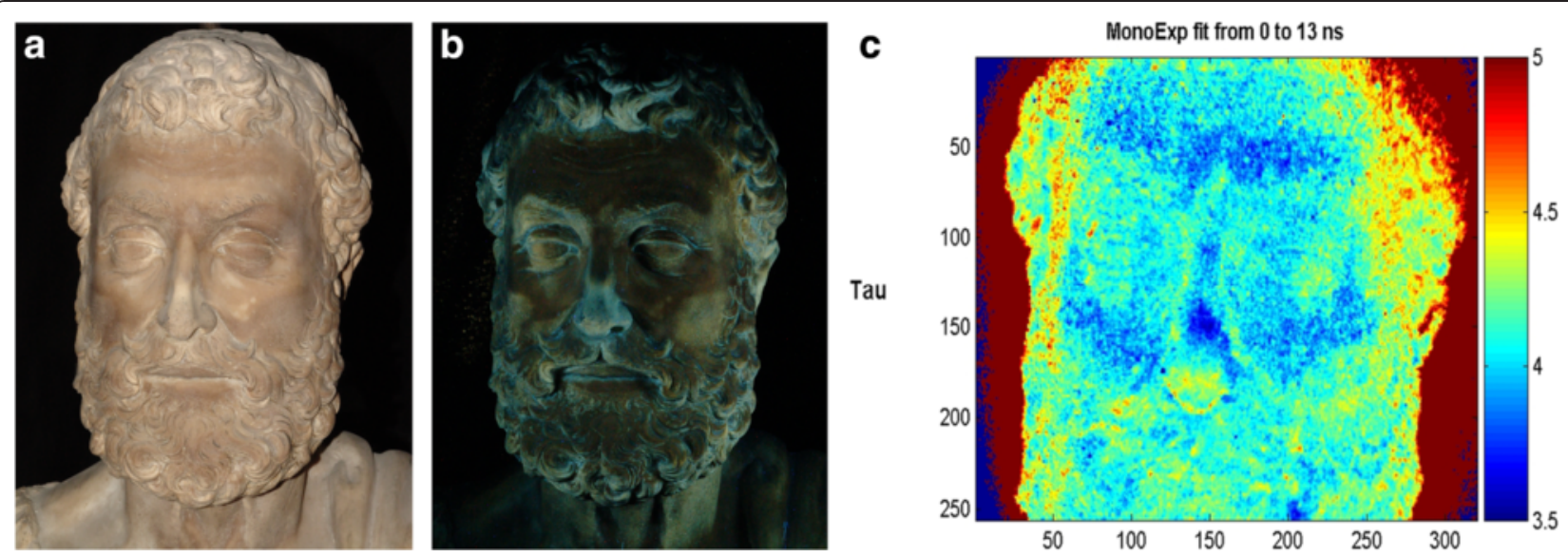

Figure 2 San Pietro, attributed to Filippo Brunelleschi, ca. 1421, detail. The brown discoloration visible on the stone surface (a). Fluorescence emission of surfaces after ultraviolet excitation test (b). Fluorescence lifetime imaging results (c). Photographs Opificio delle Pietre Dure.

matter, or metals, whereas values of $5.5-6.0$ ns are related to organic substances like wax [20].

In the FLIM analysis of areas in the face of San Pietro, where the brownish discoloration appears less pronounced under visible light, fluorescence emission has a low intensity and a lifetime of ca. 3.6 ns. In the areas where the alteration is darker, the lifetime is longer, around $4.2 \mathrm{~ns}$ (Figure 2c). Areas in the hair show a very different result, with a lifetime of ca. 4.6 ns. Areas characterized by longer times correspond to hollow zones in the statue, where the fluorescence signal is blue. These results are likely correlated with the substances used for molds. For the tip of the nose, which produces an intense blue emission under UV light, FLIM technique produces short decay lifetimes, ca. $3.6 \mathrm{~ns}$, which are comparable to those observed in areas where the brownish alteration appears lighter under visible light. Fractured surfaces, where brownish alterations are absent, show a fluorescence signal with a lifetime of ca. 5 ns.

The results of UV fluorescence tests and their in-depth study with FLIM showed that the surfaces of all the examined statues emit relevant and not uniform fluorescence signals. This means that different substances have contaminated the surfaces, probably in past restorations. However, the patterns of the emission do not seem to be connected to the examined brownish alteration because they do not produce fluorescence emissions with distinctive and homogeneous characteristics. It is important to underline that FLIM allows examination of surfaces only and hence cannot detect substances inside the stone. The lack of correlation between the brownish patterning and the fluorescence results suggested that most substances responsible for the brownish alterations are inside the stone, not on its surface.
Hypothesizing that the discoloration could be correlated to inorganic materials such as stone metal components and/or pigments, we carried out measurements with a portable XRF device to assess differences in the distribution of chemical elements between areas with and without chromatic alteration. The results were quite disappointing: the brownish areas did not contain higher amounts of elements than the light ones, nor a specific element was present exclusively on the discolored areas. Fe was detected both in the brownish areas and in the lighter ones in relatively similar amounts. Some nondark areas contained even a slightly higher amount of this element than the brownish ones.

Non-invasive analytical results were much helpful for defining which zones should be used for the unavoidable subsequent sampling.

\section{Invasive techniques}

The information obtained from the invasive analysis performed on micro-samples of brownish marble, of marble without discolorations, and of the black patina from five statues has been most significant. Crucial has been the availability of samples that could be prepared as cross sections to understand the patina and the marble structure below. Observations under the optical microscope with visible and UV illumination showed that the bronzelike patina consists of multiple layers (Figure 3a). ATRFTIR and Raman micro-spectroscopy identified ochre pigments, Prussian blue, calcium oxalates, gypsum, and ATR-FTIR also detected lipids in these layers. Under the patina, there is an area which displays a particularly strong fluorescence under UV illumination (Figure 3b), and corresponds to a region in which the marble has being transformed into calcium oxalate and gypsum. A 

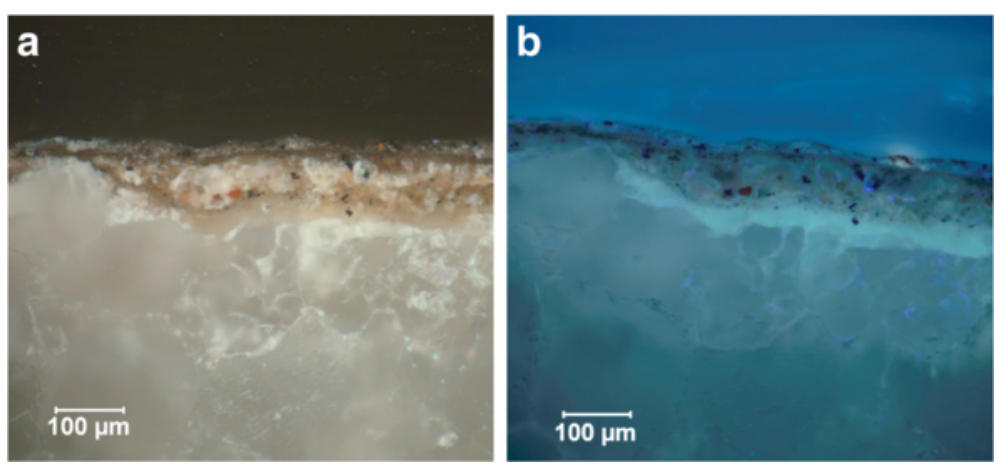

Figure 3 Quattro Santi Coronati by Nanni di Banco ca.1409-1417. Polished cross section of the bronze-like patina showing the multiple layers of the patina. Visible illumination (a). Under it, the stone displays a particularly strong fluorescence. UV illumination (b).

similar increased fluorescence is observed also in cross sections of samples taken from discolored areas of different statues. In these cases, the fluorescence is rather widespread and particularly strong in the cracks and marble crystals inside the stone, characterized by FTIR and Raman micro-spectroscopy (vide infra).

Among the various statues sampled, very important are the results obtained for Sant'Eligio. Firstly, because the cleaning of this statue was carried out solely with mechanical methods. Secondly, because it was the only statue not molded, therefore the possible interactions between the products used for molding and the past treatments is avoided. A cross section of a discolored area from Sant'Eligio shows very thin residues of patina on the marble surface and a strong fluorescence inside the stone between marble crystals (Figure 4a and b). A similar situation is found in a brown portion of the drapery of San Giacomo Maggiore (Figure 5), mostly cleaned with mechanical methods as Sant'Eligio. In both samples, the bulk of the marble in the cross sections is brownish even when observed in visible light (Figures 4a and 5).

ATR-FTIR measurements on cross sections (Figure 6a) reveal not only calcium oxalates and gypsum on the surfaces, but also to various extents within the fissuring of the marble (Figure 6b). Sometimes their presence is detected up to $500 \mu \mathrm{m}$ within the cracks of the marble. Because of the large absorption from the carbonate around $1400 \mathrm{~cm}^{-1}$, the $\mathrm{C}-\mathrm{O}$ stretching and $\mathrm{O}-\mathrm{C}=\mathrm{O}$ bending from the oxalate around the early 1300s region is detected only as a shoulder. Raman micro-spectroscopy of the fluorescent material inside the cracks confirmed, in addition to calcium carbonate (marble) and gypsum, the presence of calcium oxalate, and specifically weddellite $\left(\mathrm{CaC}_{2} \mathrm{O}_{4} \cdot 2 \mathrm{H}_{2} \mathrm{O}\right)$, particularly based on the band at $1478 \mathrm{~cm}^{-1}$ (Figure 6c). This band is well separated from the characteristic bands for marble $\left(713,1086,1439 \mathrm{~cm}^{-1}\right)$ and gypsum $(1009,1138)$, highlighted in Figure $6 \mathrm{c}$. Raman micro-spectroscopy, therefore, proved to be able to localize the calcium oxalate and discriminate between whewellite and weddellite $[21,22]$, which was difficult by ATR-FTIR, due to the large interference of the carbonate at ca. $1400 \mathrm{~cm}^{-1}$, and of the water of crystallization of gypsum (Figure 6b). Gypsum indicates weathering, while the presence of weddellite deeper in the marble indicates that organic substances had been applied to the stone, probably penetrating it to a certain extent. Over time, these
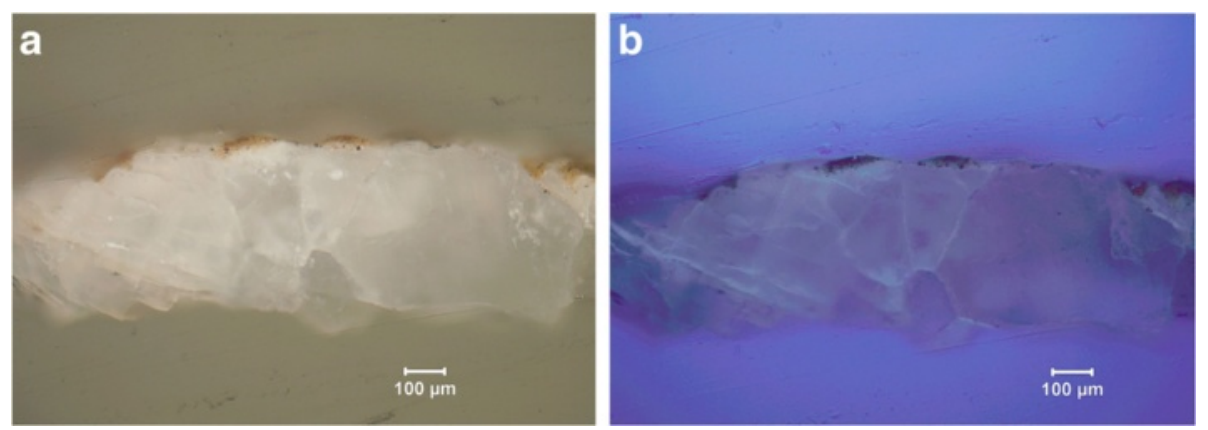

Figure 4 Sant'Eligio by Nanni di Banco ca.1417-1421. Polished cross section of a sample from a brown area. The images show the thin residues of the patina on the marble surface - visible illumination (a), and a strong fluorescence inside the stone between calcite crystals - UV illumination (b). 


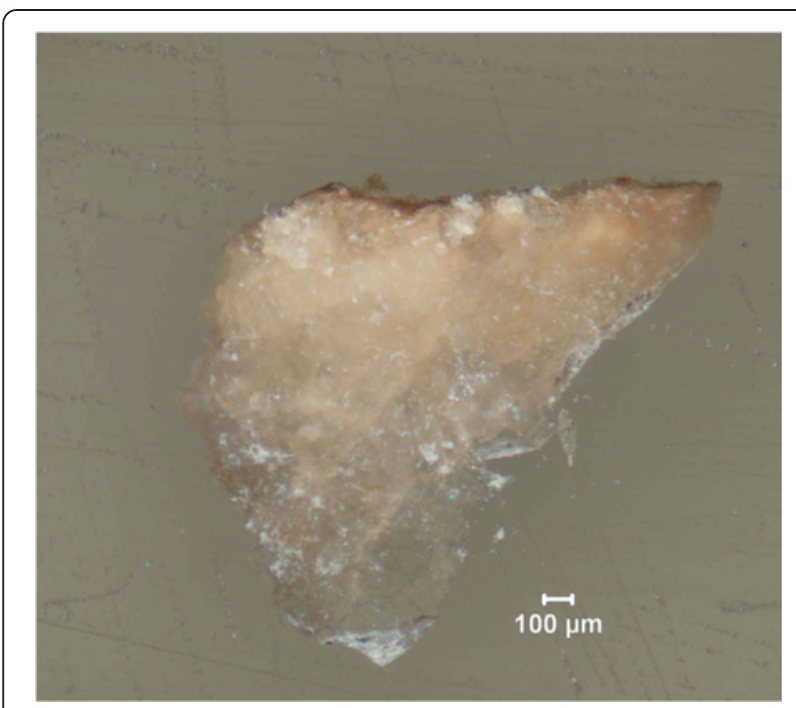

Figure 5 San Giacomo Maggiore by Niccolò di Pietro Lamberti ca. 1414. Polished cross section of a sample from a brown area showing the brown discoloration in the bulk of the marble. Visible illumination.

organic substances and their degradation products reacted with the marble and finally mineralized into calcium oxalate. This process may have been exacerbated by weathering of the stone with formation of cracks. The results are relevant because only a few studies exists where oxalates were found inside the stone [21,23], as research on calcium oxalates in cultural heritage has focussed almost exclusively on what appeared to be external patinas.

The microscopic observation of a sample from a nondiscolored area (concavity between the book and the hand holding it) of Sant'Eligio (Figure 7a) shows only a thin brown crust on the surface, while the bulk of the marble appears whitish and does not display any fluorescence under UV illumination (Figure $7 \mathrm{~b}$ and $\mathrm{c}$ ). ATRFTIR indicated no oxalates either in the crust or in the bulk of the stone (spectra not shown). The same interesting data emerged analyzing a sample from the Madonna della Rosa: no oxalates were detected within the stone. As mentioned above, this was the only sculpture not treated with the bronze-like patina, having being placed indoors in 1628.

The genesis of calcium oxalates and of patinas composed almost exclusively by these compounds has been subject of a far-reaching debate in the scientific community. The topic is still a matter of debate. Lichens and fungi's capacity to produce calcium oxalate has induced some authors to hypothesize that the patinas were originally produced by past biological growth that is no longer present today because of atmospheric pollution. Other authors, on the contrary, affirm that these layers have been formed through the transformation (by microorganisms or by abiotic agents) of organic substances applied on the stone for protective and/or aesthetic purposes [24]. Only in a very limited number of cases,
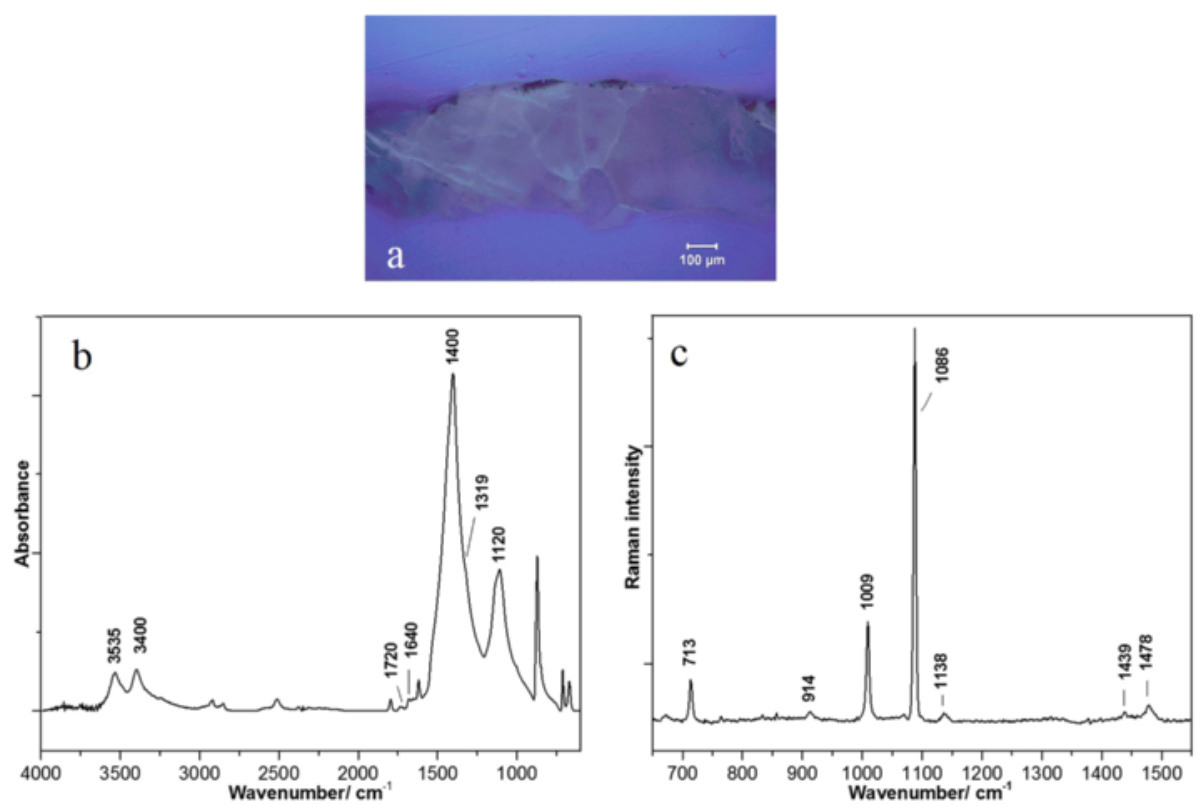

Figure 6 Sant'Eligio. Polished cross section of a sample from a brown area. UV illumination (a). Photograph Opificio delle Pietre Dure. ATR-FTIR of fluorescent material at the interface with calcite crystals, showing main characteristic absorption bands for calcium carbonate $\left(1400 \mathrm{~cm}^{-1}\right)$ and gypsum $\left(3535,3400,1120 \mathrm{~cm}^{-1}\right)$, lipids $\left(1720 \mathrm{~cm}^{-1}\right)$, and a shoulder at $1320 \mathrm{~cm}^{-1}$ from calcium oxalate (b). Raman spectrum in the same area, detailing the band from weddellite $\left(1478 \mathrm{~cm}^{-1}\right)$ and neighboring small band at $1439 \mathrm{~cm}^{-1}$ from the marble (c). The main Raman bands for the marble $\left(1086 \mathrm{~cm}^{-1}\right)$ and gypsum $\left(1009 \mathrm{~cm}^{-1}\right)$ do not interfere with the identification of weddellite. 

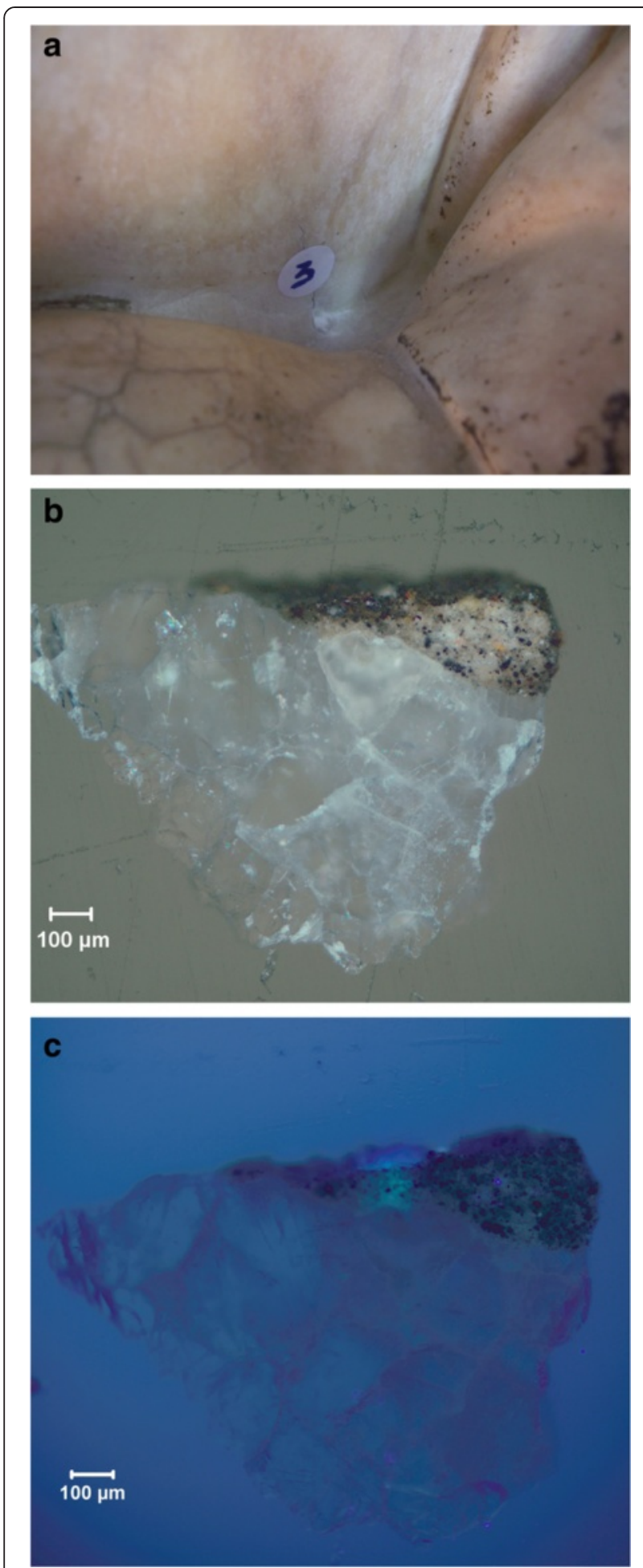

Figure 7 Sant'Eligio. Non-discolored area (a). Polished cross section of a sample from this area. The image shows a thin brown crust on the surface while the marble appears white. Visible illumination (b). No strong fluorescence detected. UV illumination (c). which cannot be generalized, the patinas could be the traces of past lichenic growths (see review in [25]). Regarding Orsanmichele statues, we cannot exclude that microrganisms partially contributed to oxalates' formation. Nonetheless, this contribution was likely limited because we did not find any remain of microrganisms in any sample observed under optical and scanning electron microscopes nor in the non-discoloured area of Sant'Eligio, a concavity between the book and the hand holding it, which is very favourable to the biofilms colonization.

ATR-FTIR of the highly discoloured marble suggested the presence of lipids inside the stone, mainly on the basis of the presence of absorption bands at 2920 and $2850 \mathrm{~cm}^{-1}$ (aliphatic $\mathrm{CH}$ stretch), $1730 \mathrm{~cm}^{-1}(\mathrm{C}=\mathrm{O}$ stretch) and around $1170 \mathrm{~cm}^{-1}$ (C-O stretch). Beside lipids, other organic compounds are often employed in art (e.g. waxes, resins), but based on the position and relative intensity of the bands, lipids are those most likely present in this case [26]. Indeed, Py-GC/MS with methylation confirmed fatty acids in all samples, including the bulk of the marble. It also showed that the bronze-like patina was applied with a drying oil binder, because of the high ratio between the combined peak areas of azelaic (d-C9) and suberic (d-C8) acids versus palmitic acid (C16:0) (Figure 8a). With the exception of the Madonna della Rosa, the data indicates that the oil from the bronze-patina penetrated the marble to different degrees, depending on the porosity of the surface, dictated by the intrinsic textural heterogeneity of the marble, as well as by its differential weathering. It is likely that linseed oil was used for such a surface treatment, but the presence of relative high levels of lauric (C12:0) and myristic (C14:0) acids, which are not usually present in discrete amounts in linseed oil, prevents a clear identification of the oil. Moreover, the py-GC/MS analyses of the marble bulk from five statues showed a distribution of fatty acids with relative high amounts of palmitic and stearic acids and variable amounts of lauric, myristic, pentadecanoic (C15:0) and heptadecanoic (C17:0) acids. This is true also for a sample taken from the statue of the Madonna dellla Rosa, which was never treated with the oil-based bronze-patina. This distribution of fatty acids is evident, for instance, in the chromatograms from the bulk of the discoloured area of Sant'Eligio and from the Madonna della Rosa (Figure 8b and c). The presence of those fatty acids with even carbon number in their chain may indicate that a dairy fat contained in milk was used, perhaps as an early coating on all statues. Pentadecanoic (C15:0) and heptadecanoic $(\mathrm{C} 17: 0)$ acids are also reported as present in relatively low amounts in milk [27]. In all cases, py-GC/MS analysis of both the surface and bulk of the marble contain unidentified nitrogen-containing compounds, which, 


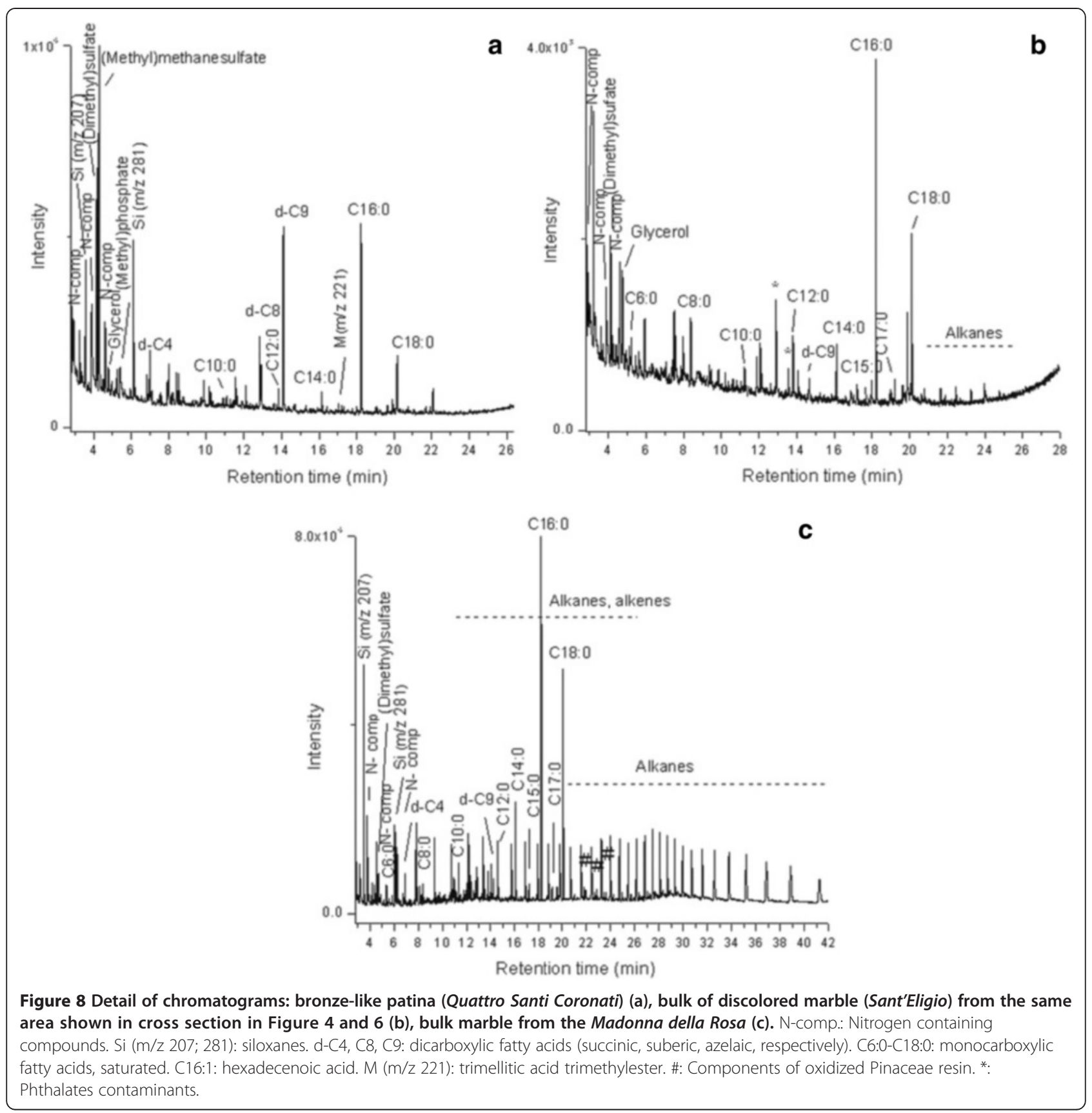

together with the methylphosphate detected, may derive from degradation of organics (i.e. protein-containing treatments).

As seen from the spectroscopic techniques, calcium oxalate plays a major role as contributor to the darkening of marble to various depths. However, the py-GC/MS techniques used did not reliably detect calcium oxalate in the scraping samples. The calcium oxalates references analyzed degraded in the analytical conditions used and the by-products overlapped with components in the early part of the chromatogram.
Regarding the origin of the lipids identified by py-GC/MS, analysis of intact triacylglycerols and hydrolysis products by other methods could elucidate their exact nature [28]. As for now we exclude that biofilms growth could have contributed to their production because: first, we did not find any biological remain in the examined samples; second, the lipids content of microbic cells is very different not only among systematic groups, but even within species belonging to the same systematic group; third, the type of fatty acids are the same in samples from five statues; fourth, it is highly unlikely if not impossible that exactly the same biofilm colonized all the statues. 
Py-GC/MS data from surface scrapings confirmed the weathering of the marble with formation of gypsum, on the basis of the high amounts of sulfate-derivatives, such as (dimethyl) sulfate and (methyl) methanesulfate.

The Madonna della Rosa, which is visibly lighter and more homogenous in color having been placed indoors in 1628, suffered less weathering and was not patinated, as mentioned earlier. In addition, its surface was protected with microcrystalline wax in the 1990s, thus further reducing any interaction of the marble with later unfavourable environmental conditions. The chromatogram of the sample from the Madonna della Rosa (Figure 8c) prominently shows residues of the 1990s restoration treatment, particularly components of microcrystalline wax (mainly series of alkenes and alkanes) and of oxidized Pinaceae resin (i.e. mainly dehydroabietic acid, or DHA, and 7-oxo-DHA) from the use of turpentine, as well as siloxanes from the silicon rubber used for molding. As a matter of fact, in many samples, with the exclusion of those from Sant'Eligio and some marble bulks, there are siloxanes, ranging from low to higher molecular weight (MW 207, 281, 267, 429) deriving from silicone rubber. The siloxanes residues were also detected by FTIR in surfaces scrapings where they could be recognized by the presence of the absorption band of the $\mathrm{Si}-\mathrm{CH}_{3}$ bond around $1260 \mathrm{~cm}^{-1}$. Other components, including polycyclic aromatic hydrocarbons (PAHs) and trimellitic acid and its derivatives are found mainly on the surface scrapings and can be attributed to environmental pollution (burning of coal).

\section{Conclusions}

The combination of results from non-invasive analyses, microscopic observations of marble samples prepared as cross sections, ATR-FTIR and micro-Raman techniques indicate that the brown colour (under visible illumination) and the strong fluorescence (under UV illumination) of the bulk of the stone correspond to areas in which calcium oxalates was detected inside the marble. Moreover, this latter information is consistent with the initial FLIM measurements, which suggested changes within the marble below the surface. Therefore, all the results confirmed that the discolouration is not a superficial film, but rather a phenomenon affecting the marble structure.

The deeper the calcium oxalate was detected the darker the marble, with no or slight discolouration occurring in the areas where calcium oxalate was absent. The differential absorption of the oil of the bronze-like patina by the weathered marble surfaces, which also might have been aggressively cleaned prior to patination, could explain the localized deeper presence of oxalates in the marble. Nitrogen-containing components were detected in the majority of the samples, as well as lipids derived from fat, perhaps from an old milk-based treatment. Further analysis, also using immunological methods, may help establish the source of proteins, if present or survived.

Under favourable environmental conditions, organic residues of the bronze-like patina and former treatments have undergone mineralization into oxalates and phosphates on the surface and in the bulk of the marble. Weathering of the marble with formation of gypsum, accompanied by increased hygroscopicity of the surfaces and the bulk due to fissuring and cracking, may have also contributed to the mineralization processes and their rate.

As already mentioned, the room in which the statues are located has large windows on all four walls, which let in a lot of light. They have a big significant effect on the museum's climatic conditions and cause overheating during some periods of the warmer months [13] (the complete set of microclimatic data, not reported in this article, will be thoroughly discussed in a further paper). The concomitant effects of light in the museum, organic components of the treatments and their mineralization, exacerbated by their depth of penetration, seem to be the most plausible cause of the localized browning of the statues.

The study also revealed the permanence of treatments with silicon rubber and wax, as well as the presence of pollutants on the stone surfaces. However, although affecting the surface properties of the statues, their nature of these compounds is unlikely the cause of the browning.

The research shows that the long-term effect of different phases of the conservation activity (from cleaning to esthetic and/or conservative treatments) can cause marble discoloration. Furthermore, the interaction between the marble, the products applied for restoration and environmental parameters is largely unknown. For these reasons, the study of marble discoloration implies a complex series of analyses, both non-invasive and invasive, which could inform on the chemical and physical changes at the surface and deeper within the marble. Although accumulating on the first hundreds of micrometers, the substances that contribute to discoloration may be present in traces and we must apply the "right" techniques to detect them.

\section{Competing interests}

The authors declare that they have no competing interests.

\section{Authors' contributions}

All authors contributed to data interpretation and to the finalization of the manuscript. All authors read and approved the final manuscript.

\section{Acknowledgements}

We would like to thank Alfredo Aldrovandi, Roberto Boddi, Andrea Cagnini, Natalia Cavalca, and Simone Porcinai of the Opificio delle Pietre Dure in Florence for their collaboration and availability to improve this research. Special thanks go to Annamaria Giusti, formerly director of the division of restoration of stone sculpture at the Opificio delle Pietre Dure, who directed 
the statues' restoration and provided precious advices and essential information. The authors would like to thank the grant program at the Metropolitan Museum of Art (MMA) for the award of an Andrew W. Mellon grant to carry out part of the study at the MMA. The authors are grateful to Silvia A. Centeno and Pablo Londero in the Department of Scientific Research at the MMA for their contribution with Raman analyses. We are grateful to Rinaldo Cubeddu, Gianluca Valentini, and Daniela Comelli of the Department of Physics, and Lucia Toniolo of the Department of Chemistry, Materials and Chemical Engineering "G. Natta" of the University of Milano, who performed and interpreted the FLIM analysis. We wish to thank Antonio Godoli, Director of the Museum of Orsanmichele, for his invaluable help in permitting us to carry out the sampling.

\section{Author details}

'Opificio delle Pietre Dure, viale Filippo Strozzi 1, 50129 Florence, Italy.

${ }^{2}$ Soprintendenza per i Beni Artistici e Storici, via Belle Arti 56, 40126 Bologna Italy. ${ }^{3}$ Metropolitan Museum of Art, 1000 5th Ave, New York, NY 10028, USA.

Received: 10 October 2014 Accepted: 10 February 2015

Published online: 01 April 2015

\section{References}

1. Macchia A, Sammartino MP, Laurenzi Tabasso M. A new method to remove copper corrosion stains from stone surfaces. J Archaeol Sci. 2011:38:1300-7.

2. Bams V, Dewaele S. Staining of white marble. Mater Charact. 2007;58:1052-62.

3. Agrawal OP, Singh T, Kharbade BV, Jain KK, Joshi GP: Discolouration of Taj Mahal marble - a case study. In: Grimstad K, editor. ICOM committee for conservation: 8th triennial meeting. Volume II. The Getty Conservation Institute; 1987: 447-52.

4. $\quad$ Bams V, de Barquin F. Décoloration des marbres. CSTC Contact. 2005;2(8):6.

5. Garcia-Valles M, Vendrell-Saz M, Krumbein WE, Urzì C. Coloured mineral coatings on monument surfaces as a result of biomineralization: the case of the Tarragona cathedral (Catalonia). Appl Geochem. 1997;12:255-66.

6. Vazquez-Calvo C, de Buergo Alvarez M, Fort R, Varas MJ. Characterization of patinas by means of microscopic techniques. Mater Charact. 2007;58:1119-32.

7. Dei L, Baglioni P, Sarti G, Ferroni E. Aging effects on ammonium carbonate/ acetone solutions and cleaning of works of art. Stud Conserv. 1996;41:9-18.

8. Doehne E, Price CA. Stone conservation. An overview of current research. 2nd ed. Los Angeles: The Getty Conservation Institute; 2010

9. Klein S, Fekrsanati F, Hildenhagen J, Dickmann K, Uphoff H, Marakis Y, et al. Discoloration of marble during laser cleaning by $\mathrm{Nd}$ :YAG laser wavelengths. Appl Surf Sci. 2001;171(3-4):242-51.

10. Sai Prasad MB, Siano S. Laser yellowing. PRAMANA, Indian Academy of Sciences. 2010;75(6):1249-52.

11. Zafiropulos V, Balas C, Manousaki A, Marakis G, Maravelaki- Kalaitzaki P, Melesanaki $\mathrm{K}$, et al. Yellowing effect and discoloration of pigments: experimental and theoretical studies. J Cult Herit. 2003;4:249s-56.

12. Oddy A. The conservation of marble sculptures in the British Museum before 1975. Stud Conserv. 2002;47:145-54.

13. Pinna D. Scientific investigations on brownish alterations on the marble statues at Orsanmichele. In: Orsanmichele and the history and preservation of the civic monument. National Gallery of Art, Washington: Yale University Press; 2012. p. 339-46.

14. Giusti A, Biliotti C, Samarelli C. Alcuni casi di utilizzo del laser nella pulitura dei marmi. OPD restauro. 1996:8:120-6.

15. Giusti A, Lalli C, Lanterna G, Matteini M, Porcinai S, Rizzi M, et al. Indagini storiche e diagnostiche per il restauro dei Quattro Santi Coronati dalla facciata di Orsanmichele a Firenze. OPD restauro. 2001;13:143-50.

16. Giusti A. Restoration of the statues in the exterior niches at Orsanmichele. In: Orsanmichele and the history and preservation of the civic monument. National Gallery of Art, Washington: Yale University Press; 2012. p. 181-6.

17. Matteini M, Moles A, Tosini I. II calco diretto dei manufatti storico-artistici mediante elastomeri siliconici: materiali e procedure. OPD restauro. 1993:5:81-6

18. Matteini M, Tosini I. Interazioni tra manufatto e agenti impiegati per i calchi (calcanti, distaccanti, film barriera). Verifiche sperimentali. In: Bresciani $E_{\text {, }}$ editor. La Cappella Colleoni in Bergamo: Le riproduzioni degli elementi decorativi. Milano: Guerini e Associati; 1995. p. 65-75.

19. Tosini I. II calco dei manufatti storico-artistici mediante elastomeri siliconici. OPD restauro. 1999;11:178-90.
20. Cubeddu R, Comelli D, Valentini G, Toniolo L, Colombo C, Sansonetti A. FLIM: fluorescence lifetime imaging. In: Bracci S, Falletti F, Matteini M, Scopigno R, editors. Exploring David: diagnostic tests and state of conservation. Florence: Giunti Editore; 2004. p. 154-60.

21. Conti C, Aliatis I, Colombo C, Greco M, Possenti E, Realini M, et al. $\mu$-Raman mapping to study calcium oxalate historical films. J Raman Spectrosc. 2012;43:1604-11.

22. Frost RL. Raman spectroscopy of natural oxalates. Anal Chim Acta. 2004;517(1):207-14

23. Conti C, Fustella G, Colombo C, Realini M, Zerbi G. Micro-Raman depth profiling on polished cross-sections: the mapping of oxalates used in protective treatment of carbonatic substrate. J Raman Spectrosc. 2008;39:1307-8

24. Bordignon F, Postorino P, Dore P, Laurenzi Tabasso M. The formation of metal oxalates in the painted layers of a medieval polychrome on stone, as revealed by micro-raman spectroscopy. Stud Conserv. 2008;53(3):158-69.

25. Pinna D, Salvadori O. Biodeterioration processes in relation to cultural heritage materials. Stone and related materials. In: Caneva G, Nugari MP, Salvadori O, editors. Plant biology for cultural heritage. Los Angeles: The Getty Conservation Institute; 2008. p. 128-43.

26. Derrick MR, Landry JM, Stulik DC. Methods in scientific examination of works of Art: infrared microspectroscopy. Los Angeles: The Getty Conservation Institute; 1991.

27. Lindmark Månsson H. Fatty acids in bovine milk fat. Food Nutr Res. 2008;52. doi: 10.3402/fnr.v52i0.1821.

28. Garnier N, Rolando C, Munk Høtje J, Tokarski C. Analysis of archaeological triacylglycerols by high resolution nanoESI, FT-ICR MS and IRMPD MS/MS: application to 5 th century BC-4th century AD oil lamps from Olbia (Ukraine). Int J Mass Spectrom. 2009;284(1):47-56.

Publish with ChemistryCentral and every
scientist can read your work free of charge
"Open access provides opportunities to our
colleagues in other parts of the globe, by allowing
anyone to view the content free of charge."
W. Jeffery Hurst, The Hershey Company.
- available free of charge to the entire scientific community
- peer reviewed and published immediately upon acceptance
- cited in PubMed and archived on PubMed Central
- yours - you keep the copyright
submit your manuscript here:
http://www.chemistrycentral.com/manuscript/

